
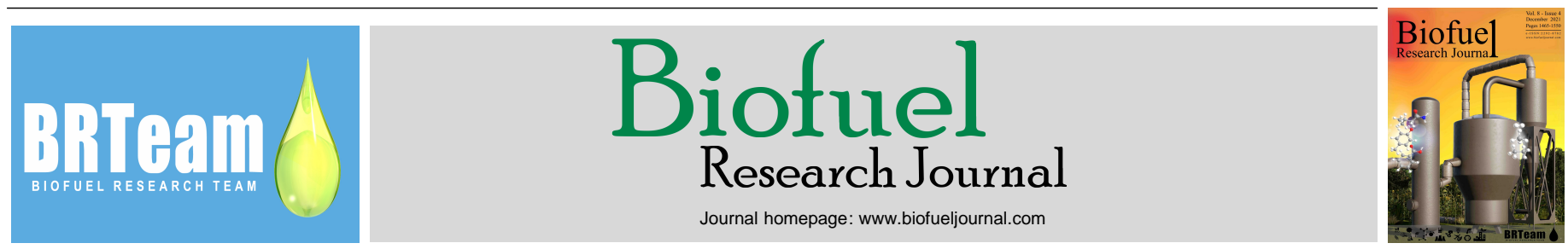

Corrigendum

\title{
Corrigendum to "A comparative evaluation of design factors on bubble column operation in photosynthetic biogas upgrading" [Biofuel Res J 8(2) (2021) 1351-1373]
}

\author{
Archishman Bose ${ }^{1,2}$, Richard O’Shea ${ }^{1,2, *}$, Richen Lin ${ }^{1,2}$, Jerry D. Murphy ${ }^{1,2}$
}

${ }^{I}$ Environmental Research Institute, MaREI Centre, University College Cork, Cork, Ireland.

${ }^{2}$ School of Engineering and Architecture, University College Cork, Cork, Ireland.

The authors of the above-referenced paper regret that there was an error with Figure 6 in the manuscript when originally submitted for publication. The correct version of Figure 6 is given below. The caption for Figure 6 in the manuscript is correct and is repeated below for reference.
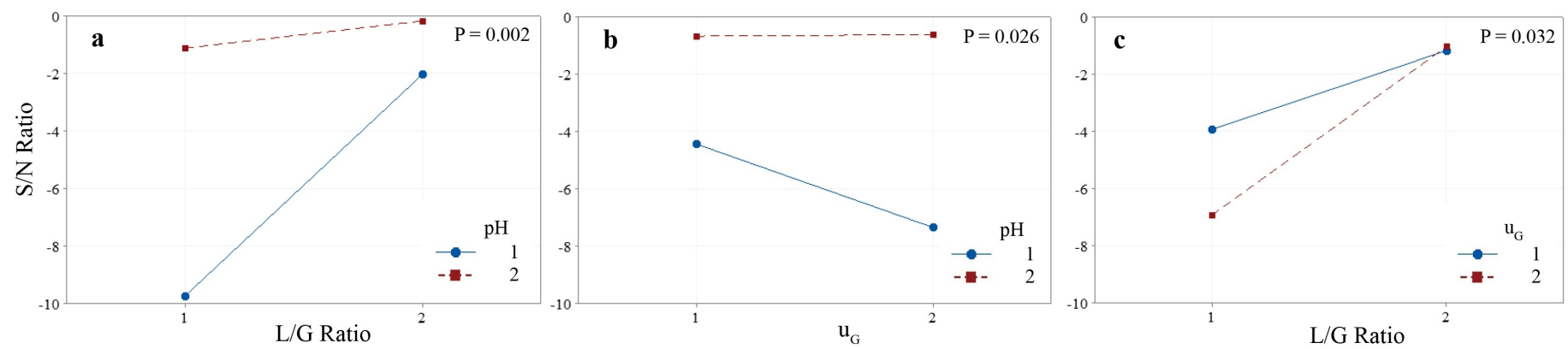

Fig. 6. Interactive effects between (a) $\mathrm{pH}$ and $\mathrm{L} / \mathrm{G}$ ratio; (b) superficial gas velocity ( $\left.\mathrm{u}_{\mathrm{G}}\right)$ and $\mathrm{pH}$; and (c) superficial gas velocity $\left(\mathrm{u}_{\mathrm{G}}\right)$ and $\mathrm{L} / \mathrm{G}$ ratio on $\mathrm{CO}{ }_{2}$ removal efficiency.

DOI of original article: 10.18331/BRJ2021.8.2.2

* Corresponding author at: Tel.: +353 21490197

E-mail address: richard.oshea@ucc.ie

Please cite this article as: Bose A., O'Shea R., Lin R., Murphy J.D. Corrigendum to "A comparative evaluation of design factors on bubble column operation in photosynthetic biogas upgrading" [Biofuel Res J 8(2) (2021) 1351-1373]. Biofuel Research Journal 32 (2021) 1550. DOI: 10.18331/BRJ2021.8.4.5 